\title{
PATH-DEPENDENCE, EXPECTATIVAS E REGULAÇÃO ECONÔMICA ELEMENTOS DE ANÁLISE A PARTIR DE UMA PERSPECTIVA PÓS-KEYNESIANA*
}

\author{
Ricardo Ramalhete Moreira ${ }^{* *}$
}

Alain Herscovici ${ }^{* *}$

RESUMO O artigo busca fazer uma relação entre a ocorrência de path-dependence, a natureza expectacional do investimento e as flutuações econômicas, a partir de um referencial pós-keynesiano de análise. Em um ambiente não-ergódico, a fim de que o sistema tenha uma relativa estabilidade no tempo, a regulação econômica requer muito mais do que simples ajustamentos incrementais. Tornam-se necessárias, e possíveis, modificações qualitativas do sistema econômico. Tais modificações são analisadas a partir do conceito de bifurcação.

Palavras-chave: path-dependence; investimento; incerteza; regulação econômica; bifurcação

Código JEL: B41, D81, E12

\section{PATH-DEPENDENCE, EXPECTATIONS AND ECONOMIC REGULATION: \\ ELEMENTS OF ANALYSIS FROM A POST-KEYNESIAN PERSPECTIVE}

ABSTRACT The article looks for making a relation between the path-dependence, the expectational nature of investment and the economic fluctuations, from a post-

\footnotetext{
* Artigo recebido em 16 de novembro de 2005.

** Mestre em Teoria Econômica pela UFES e membro do Grupo de Estudo em Macroeconomia (GREM) do Departamento de Economia da UFES.

*** Doutor em Economia pelas Universidades de Paris I Panthéon-Sorbonne e de Amiens, coordenador do Grupo de Estudo em Macroeconomia (GREM) do Departamento de Economia da UFES, professor e coordenador do programa de pós-graduação em economia da UFES, e-mail: alhersco.vix@ terra.com.br
} 
keynesian analysis view. On a non-ergodic environment, in order to the system receive a relative stability through time, the economic regulation requires much more than additional adjustments. It makes necessary, and possible, qualitative modifications of the economic system. These modifications are analyzed by the concept of bifurcation.

Key words: path-dependence; investment; uncertainty; economic regulation; bifurcation 


\section{INTRODUÇÃO}

É possível identificar na economia algumas abordagens que vêem o longo prazo do sistema econômico como sendo predeterminado e independente das ocorrências de curto prazo. As análises apoiadas na lei de Say, a matriz neoclássica walrasiana e os modelos novo-clássicos são alguns exemplos dessas abordagens. Pode-se afirmar que nelas não há o fenômeno de pathdependence, este entendido como o fato de os valores a longo período do sistema serem uma função das ocorrências de curto prazo.

A existência de path-dependence expressa o caráter irreversível e histórico do sistema estudado. O passado é irrevogável, não podendo ser reproduzido com exatidão, na medida em que as condições iniciais não são mais as mesmas; o futuro, por sua vez, está somente no imaginário dos agentes: $e x$ ante, o futuro ainda não existe.

A partir do momento em que é aceita a ocorrência de path-dependence no sistema econômico, a incerteza decorrente disso e a não-neutralidade da moeda fazem com que as flutuações econômicas (ou desequilíbrios) tenham uma determinação endógena. Além disso, os desequilíbrios passam a ser considerados sistemáticos, e não mais aleatórios, havendo necessidade de uma regulação do sistema por parte das instituições responsáveis. A dinâmica cíclica da economia pode ser entendida a partir da divergência entre valores ex ante e expost, sob uma realidade não-ergódica.

A não-ergodicidade, por sua vez, refere-se à possibilidade de haver mudanças estruturais no sistema econômico. $\mathrm{O}$ fato de mudanças qualitativas serem possíveis e, até certa medida, imprevisíveis faz com que a base de nosso conhecimento acerca do futuro não seja totalmente confiável. Destarte, o reconhecimento de processos de path-dependence implica a não-ergodicidade do sistema econômico, o que, por sua vez, constitui-se na dimensão ontológica da noção de incerteza.

Ao considerar mais detidamente essas questões, mediante um referencial pós-keynesiano, o presente trabalho segue a seguinte estrutura analítica: na seção 1, são estudados o fenômeno de path-dependence e as propriedades essenciais da moeda, assim como o conflito entre ruptura e regulação, o papel das expectativas e a natureza endógena das flutuações econômicas. $\mathrm{Na}$ seção 2, abordamos a tendência de instabilidade estrutural no sistema econômico e a necessidade de regulação do mesmo, assim como sua natu- 
reza não ergódica, a aplicação do conceito de bifurcação em economia e o modelo de Harrod (1938) como um case apropriado de estudo no presente contexto analítico.

\section{PATH-DEPENDENCE, INCERTEZA E MOEDA}

\subsection{Path-dependence e a inexistência do futuro ex ante}

É possível identificar, na Economia, algumas abordagens que estão enraizadas em uma concepção de futuro predeterminado. Na análise feita por Say (1803), por exemplo, os desequilíbrios setoriais são provisórios e não têm condições de gerar um desequilíbrio macroeconômico permanente (Herscovici, 2002: 268). O futuro, na lei de Say, ${ }^{1}$ está predeterminado e corresponde à situação em que a oferta global é igual à demanda global.

A análise walrasiana é um pouco mais radical que a descrita pela economia de Say. Isso porque Walras possui um modelo de equilíbrio puro. As trocas reais, intermediadas pela moeda, são realizadas somente quando os preços de equilíbrio já tiverem sido determinados. Esses preços de equilíbrio são determinados, ex ante, pelo leiloeiro. O modelo de equilíbrio geral walrasiano nada pode informar acerca do processo de ajustamento pelo qual aqueles preços são alcançados. Posições de desequilíbrio são tidas como ilógicas, uma vez que não dão solução ao sistema de equações simultâneas (Vercelli, 1991). Neste sentido, em Walras, o tempo é reversível, ou seja, passado, presente e futuro possuem a mesma configuração de equilíbrio.

Nos modelos novo-clássicos, propostos por Lucas, Sargent e Wallace a partir da década de 1970, não há muita diferença. Apesar de conceberem o sistema econômico como um processo estocástico ou probabilista, a análise supõe que os processos estocásticos envolvidos são estacionários. As hipóteses de expectativas racionais ${ }^{2}$ e markets-clearing contínuo ${ }^{3}$ concedem ao sistema econômico uma trajetória de equilíbrio estável (Ferrari, 2001). As flutuações econômicas são originadas apenas em perturbações estocásticas e exógenas, cuja distribuição de probabilidade é suposta como tendo média igual a zero e variância constante ${ }^{4}$ no tempo (Barbosa, 1992). Ademais, como os processos estocásticos envolvidos são estacionários, a função distribuição de probabilidade que governa os possíveis eventos é inflexível. Logo, o conjunto de eventos futuros possíveis, com suas respectivas pro- 
babilidades, pode ser conhecido a partir das informações passadas, extraídas dos preços de mercado. ${ }^{5}$ Nas palavras de Davidson (1996), os modelos novo-clássicos apresentam uma realidade imutável.

Em todas essas abordagens, não há espaço para modificações estruturais ${ }^{6}$ na economia. Em outras palavras, os possíveis desequilíbrios ou flutuações não alteram a trajetória do sistema a longo prazo: não existe path-dependence. A existência de uma trajetória dependente (path-dependence) pode ser interpretada como: (i) as evoluções futuras do sistema dependem de seus estados presentes e passados (Herscovici, 2003: 6) ou (ii) os valores a longo período do sistema são uma função das ocorrências de curto prazo. Tem-se que:

$L P=\phi(C P)$, onde $L P$ são os valores a longo período e $C P$ as ocorrências de curto prazo.

A existência de path-dependence expressa o caráter irreversível e histórico do sistema estudado. O passado é irrevogável, não podendo ser reproduzido com exatidão, na medida em que as condições iniciais não são mais as mesmas; o futuro, por sua vez, está somente no imaginário dos agentes: ex ante, o futuro ainda não existe. Por outro lado, o fato de que a construção do futuro será o resultado de um processo de decisões descentralizadas torna-o sujeito a configurações imprevisíveis.

Diante do exposto acima, a possibilidade de haver uma prevalência do equilíbrio $^{7}$ em uma economia monetária de produção ${ }^{8}$ é desprezível. Para que o equilíbrio seja alcançado, é preciso haver estabilidade suficiente na estrutura qualitativa do sistema, a fim de que, mediante aprendizado, os agentes possam conhecer e escolher a melhor opção dentre todas as existentes. Todavia, no caso de essa estrutura estar se modificando ao longo do tempo, nada garante que o ajustamento dos agentes seja rápido o suficiente para que o equilíbrio seja alcançado. Além disso, a complexidade das leis determinantes de uma dada estrutura pode ser de tal monta que seria necessário um prazo temporal infinito com vistas ao "pleno aprendizado" dos indivíduos.

Um outro empecilho que se coloca no caminho do uso do equilíbrio como instrumento de análise macroeconômica diz respeito ao investimento, tal como descrito pela Teoria Geral de Keynes (1936). Como é sabido, em Keynes, o investimento não está associado às rendas correntes, mas aos 
resultados futuros esperados. ${ }^{9}$ A ocorrência de path-dependence torna pouco provável uma igualdade entre estimativas ex ante e resultados ex post. Segundo Herscovici (2002b), a dinâmica cíclica da economia pode ser entendida a partir da divergência entre valores ex ante e expost.

Uma abordagem que considere a existência de modificações estruturais, cuja ocorrência torna incerta a configuração futura do sistema, precisa dar ênfase ao processo de ajustamento dos agentes em posições de desequilíbrio. Trata-se de uma economia do desequilíbrio (Duménil e Lévy, 2001), na qual as variações de renda e emprego ${ }^{10}$ são compreendidas como ocorrendo em situações de (a) divergência entre oferta global e demanda global e (b) reavaliação de expectativas por parte dos agentes.

\subsection{A moeda e suas propriedades essenciais: regulação ou ruptura?}

No intuito de se compreender a dinâmica das flutuações em uma economia industrial moderna, é necessário fazer uma análise da natureza da moeda. Isso remete à revolução levantada pela Teoria Geral (1936). Keynes rompera com o chamado axioma dos reais, ${ }^{11}$ tão caro ao pensamento neoclássico. Esse axioma implica a suposição de que os agentes só procuram ativos reais, tais como bens, descanso ou esforço. Significa que não existe nenhum tipo de "ilusão monetária" em meio aos agentes econômicos.

Ao adotar o axioma dos reais, o pensamento neoclássico (e também o novo-clássico) considera a moeda como uma sombra, cuja projeção não possui qualquer influência sobre a verdadeira substância da economia: o setor real. O produto real é tido como o resultado das decisões racionais dos agentes, tomadas com base no conhecimento da dotação de recursos, das preferências e dos preços relativos (Davidson, 2003).

Todavia, para que Keynes conseguisse formar uma teoria monetária coerente, era preciso rejeitar o axioma dos reais:

A teoria almejada por mim trataria (...) de uma economia na qual a moeda tem um papel próprio, afeta os motivos e decisões e é, em suma, um fator operante na situação [econômica]. (1973: 408-409)

Destarte, rejeitar o axioma dos reais implica o reconhecimento da moeda como um fenômeno real, ou seja, money matters, tanto no curto prazo quanto no longo prazo (Davidson, 1996). A moeda também deve estar presente, 
enquanto variável explicativa, na formulação de qualquer função-utilidade. Quais seriam, afinal, as características da moeda, responsáveis pela sua nãoneutralidade? Basicamente, a moeda possui duas propriedades essenciais (Keynes, 1936: 180-185):

- Sua elasticidade de produção é, se não nula, muito baixa: "todos os ativos líquidos são não produzíveis pelo uso de trabalho no setor privado" (Davidson, 1999: 54). Logo, o aumento da demanda por moeda não permite que os trabalhadores desempregados sejam empregados na produção de mais moeda. ${ }^{12}$

- Sua elasticidade de substituição também, se não nula, é desprezível. Significa que, mesmo que o valor de troca da moeda cresça, não surge qualquer tendência para substituí-la por outro ativo reprodutível por trabalho. Não existe, portanto, substituição bruta significativa entre ativos líquidos não reprodutíveis e os produtos do trabalho na indústria (Davidson, op. cit.: 54).

Enquanto os detentores de riqueza desejam conservá-la sob a forma de ativos líquidos cujas elasticidades de produção e substituição são quase nulas, a economia pode ter uma trajetória sem pleno emprego. Em outras palavras, quando existem outras formas de usar as poupanças, além dos ativos produzíveis pelo trabalho, pode haver desemprego involuntário.

Em uma economia monetária, reter moeda não é irracional, uma vez que ela funciona como uma defesa contra um futuro indeterminado. Neste sentido, se a incerteza

levar os agentes a decidir reter riqueza em forma monetária ao invés de ativos reprodutíveis, o emprego que é perdido na produção destes últimos não é recuperado na produção de dinheiro. (Carvalho, 1992: 180)

Os pós-keynesianos, de uma maneira geral, enfatizam a importância da moeda enquanto um meio pelo qual os contratos são fixados na economia. A decisão de investir está associada à projeção de um futuro ainda inexistente. O empresário precisa se comprometer, ex ante, com um fluxo de pagamentos (débitos) ao longo do tempo: pagamento de juros, de salários, aos fornecedores etc.; por outro lado, o fluxo de receitas das vendas é uma variável ex post, estando o empresário suscetível a frustrações em suas expectativas iniciais. Os contratos monetários teriam a função de reduzir a imprevisibilidade desses fluxos de renda. ${ }^{13}$ 
Segundo Carvalho (1992), quanto maior o número de contratos regendo transações, maior o número de preços futuros conhecidos no presente. Segundo ainda Ferrari e Conceição (2001), a moeda concede segurança contra a incerteza do futuro, mediante contratos monetários, unindo passado, presente e futuro e, assim, coordenando a atividade econômica.

À primeira vista, algo parece contraditório: a moeda que, ao ser retida em detrimento dos bens produzidos pelo trabalho, gera desemprego e instabilidades é a mesma que permite coordenação e previsibilidade, mediante os contratos monetários? Afinal, a moeda é o refúgio contra a incerteza ou a causa da incerteza? Como apontara Kregel (1980), se os salários são pagos em moeda, nada garante que a renda corrente seja igual aos gastos correntes e, assim, rompe-se com a lei de Say. Por outro lado, se os agentes se comprometem, por meio de contratos, a comprar e vender bens ou serviços por um prazo $X$, ao preço $Y$, há, sem dúvida, um amortecimento da incerteza, assim como uma redução do hiato potencial entre renda e gasto correntes.

Trata-se de uma contradição apenas aparente. Em períodos de otimismo dos agentes, quando há um processo de expansão cumulativa, os contratos são facilmente acertados, uma vez que a preferência pela liquidez é reduzida. De fato, nesses episódios históricos, parece haver uma diminuição da incerteza. Todavia, como é sabido, a economia move-se em trajetória cíclica. Dado o turning-point do ciclo, há uma inversão das expectativas. A demanda efetiva entra em colapso, contratos antes acertados não são honrados, ${ }^{14}$ novos contratos são postergados e há um aumento da preferência pela liquidez. Destarte, verifica-se uma tensão contínua e histórica, ao longo do ciclo econômico, entre a preferência por liquidez e o acerto de contratos. Uma tensão entre ruptura e regulação.

\subsection{Expectativas e flutuações cíclicas}

Uma vez aceita a existência de path-dependence, i.e., o fato de que o futuro é, ex ante, inexistente e apenas existirá enquanto uma construção pelas decisões descentralizadas dos agentes, a estes resta decidir acerca dos investimentos com base em expectativas. Kregel (1980) afirma:

In an economy where the expenditure of current savings at a future date cannot be foreseen with certainty, entrepreneurs will have to make current decisions on investment expenditure on the basis of the profits they expect to earn during the expected life of the project. (Kregel, op. cit.: 35) 
Se considerarmos a poupança global $(P g)$ como sendo função dos lucros realizados $(L r)$, enquanto o investimento $(I g)$ é função dos lucros previstos $(L p)$, temos as seguintes funções: ${ }^{15}$

(i) $I g=f(L p)$

(ii) $P g=g(L r)$

A estabilidade do equilíbrio na lei de Say implica a igualdade $L r=L p$. Isso, contudo, só pode ser concebido com a ausência de incerteza. Adotando-se a ocorrência de modificações estruturais - o que torna o conhecimento corrente não totalmente confiável enquanto instrumento de previsão - e a existência de uma moeda não neutra, nada garante a igualdade entre lucros previstos e lucros realizados. Segundo Kregel (1980),

Keynes introduced a distinction between decisions based on realized results and those based on expected results (consuptiom and investment). (Kregel, op. cit.: 35)

A dinâmica do investimento, com sua volatilidade, pode ser concebida como resultado de uma divergência sistemática, dado um futuro indeterminado, entre valores esperados e realizados. Todavia, é preciso frisar que, mesmo existindo uma possível equivalência de curto prazo entre valores esperados e valores realizados, os investimentos continuam tendo uma natureza instável, dado seu horizonte de longo prazo. A questão é que o cálculo das rendas esperadas para um bem de capital qualquer é feita como sobre "areia movediça", ou seja,

o fator de maior importância é a extrema precariedade da base do conhecimento sobre o qual temos de fazer os nossos cálculos das rendas esperadas. O nosso conhecimento dos fatores que regularão a renda de um investimento alguns anos mais tarde é, em geral, muito limitado e, freqüentemente, desprezível. (Keynes, 1936: 125)

Para Ferrari e Conceição (2001: 3), as crises de superprodução no capitalismo seriam causadas pela interação entre incerteza e preferência pela liquidez. Em momentos nos quais os agentes perdem a confiança nos bens de capital, eles preferem empregar sua riqueza sob a forma de ativos líquidos não reprodutíveis pelo trabalho. Disso resultaria a insuficiência de demanda, conduzindo a economia ao processo de recessão.

Apesar de verdadeiro, o raciocínio acima precisa ser mais abrangente. Isto porque a incerteza e a moeda não são responsáveis apenas por crises 
de superprodução, mas também por "crises" de subprodução, ou seja, pelos booms, nos quais o investimento torna-se superior à poupança. ${ }^{16} \mathrm{~A}$ incerteza permite aos agentes incorrerem em fases de otimismo exacerbado. Nessas fases, a preferência pela liquidez é fortemente reduzida, os contratos facilmente acertados e o emprego aumenta em trajetória crescente. Todavia, há uma gama de trabalhadores cujo emprego não será sustentado, na medida em que o ciclo alcançar o turning-point. Quanto maior for a especialização dos trabalhadores adicionais em setores que cresceram de forma exagerada no boom, maior será o desemprego, e sua duração, no momento em que as expectativas forem invertidas. Assim, todo boom tem em seu funcionamento as sementes de uma futura recessão. Keynes (1936) também já apontara para os males da volatilidade do investimento.

O presente trabalho não apenas defende a tese de que o sistema econômico capitalista, deixado à sorte das livres forças de mercado, possui uma trajetória de desequilíbrio sistemático, mas também de que esses desequilíbrios podem ser amplificados temporalmente, na ausência de regulação adequada.

Para tanto, observem-se as seguintes situações. Tenha-se, por motivo de simplificação, a economia como sendo dividida em dois setores: o de bens de consumo (setor 1) e o de bens de investimento (setor 2). Dada uma frustração das expectativas de curto prazo $^{17}$ no setor 1 , os empresários deste setor podem antecipar uma redução na demanda futura por seus bens, em comparação ao que era antes previsto, ou seja, as expectativas de longo pra$z^{18}$ no setor 1 também são afetadas pelo desequilíbrio inicial. A conseqüente redução dos investimentos pelo setor 1, por sua vez, tem uma impacto direto sobre o setor 2. Este, ao ver frustradas suas próprias expectativas de curto prazo, também pode alterar suas expectativas de longo prazo. Há um processo de recessão cumulativa. Isso decorre do fato de que, na ausência de informação confiável sobre o futuro, as expectativas dos agentes são sensíveis aos eventos correntes (Kregel, 1976, 1980).

Imagine-se também a situação em que há uma redução corrente de preços e salários. Para o pensamento convencional, isso resultaria em um aumento da demanda corrente. Contudo, caso os agentes antecipem uma nova redução dos preços no futuro próximo, as compras (inclusive de bens de capital) podem ser adiadas, o que reduziria a demanda corrente, levando a uma nova diminuição dos preços (Amadeo e Dutt, 2003). 
Por outro lado, em períodos de otimismo exacerbado, as expectativas podem criar reduções sucessivas na taxa de juros. Uma redução inicial nesta taxa é seguida de uma nova redução, na medida em que os agentes antecipam futuras reduções na taxa de juros, o que diminui a preferência pela liquidez no presente. Trata-se de um mecanismo de profecia auto-realizável.

Como será melhor visto a seguir, é possível, a partir do modelo de Harrod, ${ }^{19}$ romper-se com a dicotomia ciclo/tendência (Herscovici, 2002). Podese dizer que os desequilíbrios a curto prazo, por meio de seu impacto sobre os parâmetros estruturais do sistema, podem gerar desequilíbrios a longo prazo. O modelo de Harrod descreve a natureza instável da economia capitalista, na qual desvios iniciais da posição de equilíbrio podem ser amplificados no tempo, caso não haja formas alternativas de regulação fora desse mesmo equilíbrio.

\section{MODIFICAÇÕES ESTRUTURAIS E REGULAÇÃO}

\subsection{A não-ergodicidade do sistema econômico:}

\section{a dimensão ontológica da incerteza}

O conceito de ergodicidade (ou de não-ergodicidade) representa uma descrição estatística dos universos de análise nos quais existe certeza (ou incerteza) acerca dos eventos futuros. Em termos estatísticos, a ergodicidade implica a igualdade entre médias espaciais e temporais de processos estocásticos. ${ }^{20}$ Uma estatística (média, desvio-padrão etc.) temporal forma-se com base em uma única realização do evento $X$ sobre cada período de uma série temporal qualquer; uma estatística (média, desvio-padrão etc.) espacial, por sua vez, forma-se mediante uma ampla gama de realizações do evento $X$ em um período fixo do tempo. Caso o processo estocástico seja ergódico, para infinitas realizações, haverá equivalência entre as médias temporais e espaciais (Davidson, 1996: 480).

O axioma ergódico realiza uma verdadeira espacialização do tempo. ${ }^{21}$ Em sistemas cujo tempo é igualado à variável espaço, tudo se passa como se fosse possível, ao analista-observador, conhecer todos os eventos futuros, assim como os eventos passados e presentes. A partir das condições iniciais dadas, e da lei geral que predetermina a trajetória do sistema, tal como ocor- 
re na dinâmica newtoniana, é possível prever a posição do sistema em qualquer ponto do tempo. Num mundo onde haja ergodicidade não pode haver incerteza. ${ }^{22}$ Isso se traduz na possibilidade de os preços cumprirem uma função sinalizadora aos agentes.

Por assumir que a atividade econômica ocorra sob condições de certeza acerca dos eventos futuros, os economistas neoclássicos presumiam que os agentes tinham conhecimento perfeito de uma realidade econômica programada e imutável, a qual governaria todos os eventos passados, presentes e futuros. Neste sentido, uma economia segundo os axiomas neoclássicos está sujeita à invariabilidade, ${ }^{23}$ ou seja, não é suscetível de sofrer mudanças induzidas pela ação humana. ${ }^{24}$

Sendo a realidade ergódica, a taxa de juros informa como uma variação no consumo presente é traduzida na variação do consumo futuro. ${ }^{25} \mathrm{Em}$ uma versão neoclássica, o consumidor realiza uma escolha entre consumo presente e futuro, estando diante de sua restrição orçamentária intertemporal. Ele otimiza sua utilidade total quando sua curva de indiferença (entre consumo presente e futuro) tangencia sua restrição orçamentária intertemporal. ${ }^{26}$ Evidentemente, neste caso, o consumidor possui plena certeza acerca de sua função-objetivo, sendo a posse de moeda uma escolha irracional.

Neste sentido, percebe-se como a informação está diretamente ligada à questão do equilíbrio em economia. Na possibilidade de o mercado fornecer informações confiáveis acerca da estrutura qualitativa do sistema, e sendo esta estrutura estável no tempo (ergodicidade), o equilíbrio torna-se uma simples conseqüência. Os agentes aprendem qual é a decisão ótima, dada a estrutura do sistema. Vercelli (1991) chamaria esse comportamento de adaptativo. ${ }^{27}$ Para isso, supõe-se um universo ergódico.

Por outro lado, a não-ergodicidade refere-se à possibilidade de haver mudanças estruturais no sistema econômico. $\mathrm{O}$ fato de mudanças qualitativas serem possíveis e, em certa medida, imprevisíveis faz com que a base de nosso conhecimento acerca do futuro não seja totalmente confiável. Destarte, o reconhecimento de processos de path-dependence implica não-ergodicidade do sistema econômico, o que, por sua vez, constitui-se na dimensão ontológica da noção de incerteza. ${ }^{28}$ 


\subsection{0 conceito de bifurcação: relativização do dilema estabilidade versus instabilidade}

Nosso universo seguiu um caminho de bifurcações sucessivas: poderia ter seguido outros. Talvez possamos dizer o mesmo sobre a vida de cada um de nós. (Prigogine, 1996: 75)

O conceito de bifurcação, originado em meio à termodinâmica do desequilíbrio, permite dar conta do caráter histórico de um dado sistema estudado. A existência de pontos de bifurcação expressa o "grau de liberdade" do sistema, ou seja, sua capacidade de escolher formas alternativas de regulação (Herscovici, 2004). São pontos em que o sistema se depara com a dimensão probabilística (ou probabilista) de sua trajetória. Nos pontos de bifurcação não há nenhum determinismo possível (Prigogine, 1996: 73).

Uma vez que o sistema escolha, a partir de uma bifurcação, uma certa forma de regulação, não há meios pelos quais fazê-lo retornar ao modo de regulação anterior. Sua trajetória é histórica e irreversível (Herscovici, 2004: 814). No que concerne às instituições, por exemplo, as novas convenções adotadas pelos agentes são responsáveis pela "destruição" das convenções antigas. Isso remete ao processo de destruição criativa concernente às inovações tecnológicas, descrito por Schumpeter. Pode-se também dizer que as decisões de investimento, tais como descritas por Keynes, apresentam uma certa irreversibilidade: contratam-se débitos futuros, sem a garantia de retorno do novo investimento. Sabendo deste caráter irreversível e incerto dos bens de capital, o empresário pode escolher formas mais líquidas de empregar sua renda.

Portanto, a estrutura qualitativa presente do sistema está ligada às suas evoluções passadas. Caso, diante das bifurcações encontradas, as escolhas tivessem sido diferentes, a estrutura qualitativa presente poderia ser radicalmente distinta. De maneira semelhante, pode-se dizer que o estado futuro do sistema dependerá das trajetórias escolhidas no presente. Logo, estamos falando de uma análise que considera path-dependence e o fato de haver uma sensibilidade às condições iniciais. ${ }^{29}$

Não existem bifurcações em um sistema cuja trajetória pode ser deduzida a partir do conhecimento de suas condições iniciais. Neste caso, a trajetória do sistema é determinista. A introdução de pontos de bifurcação, 
portanto, concede uma natureza estatística aos fenômenos estudados. Por outro lado, como assegurou Prigogine (1996), são as flutuações as responsáveis pela escolha da evolução alternativa a ser adotada pelo sistema. Desta forma, se em zonas históricas de estabilidade as flutuações são irrelevantes (pois o sistema é convergente), longe do equilíbrio ocorre algo diferente: o sistema encontra pontos de bifurcação e, a partir daí, as flutuações têm uma função criativa no sistema. Isso nos força a recusar as análises econômicas deterministas do mainstream: (i) estas análises não vêem a possibilidade de uma determinação endógena das flutuações e das alterações estruturais do sistema; (ii) elas não compreendem como as flutuações podem ter um papel "diretor" nas trajetórias históricas e irreversíveis do sistema. Eis aqui uma forma de conceber os pontos de bifurcação:

$Y(t)=Y_{0} e^{-a t}$, em que $Y(t)$ representa a posição do sistema em função do tempo $t$. O sistema possui uma certa dinâmica fora do equilíbrio, dados o desvio inicial $Y_{0}$ (refere-se ao valor de $Y$ quando $t=0$ ) e o valor da constante $a$. Imagine-se que:

(i) $\mathrm{Se}-\lambda<\mathrm{Y}_{0}-\lambda$, então a $>0$.

(ii) Se $-\lambda \geq \mathrm{Y}_{0}$ ou $\lambda, \leq Y_{0}$, então $a<0$, onde $\lambda$ representa um ponto de bifurcação.

A função (1) concede a solução de uma equação diferencial linear de primeira ordem com steady-state igual a zero. Ou seja, o equilíbrio é alcançado quando o sistema $Y(t)$ converge assintoticamente para zero. Todavia, o fato de o sistema ser convergente depende da magnitude do desvio inicial. A proposição $i$ apresenta o que chamo um intervalo de convergência. Caso o desequilíbrio inicial esteja dentro deste intervalo, a constante $a$ será positiva e $Y(t)$ tenderá a zero quando $t$ aumentar (neste caso, o sistema converge). Por outro lado, a proposição (ii) apresenta as condições de instabilidade do sistema. Se o desvio inicial for igual ou superior a $\lambda$, ou igual ou inferior a $-\lambda$, então o sistema entra em uma zona de instabilidade. O desequilíbrio inicial cresce com o tempo (o sistema diverge).

Pode-se visualizar esse fenômeno na figura 1.

Dessa maneira, fala-se em uma convergência condicional. $O$ desequilíbrio, a partir de certo ponto, pode alterar a estrutura qualitativa do sistema, tornando-o instável. Neste sentido, $\lambda$ e $-\lambda$ são pontos de bifurcação. A estabilidade do equilíbrio não é postulada como sendo universal e necessária, 
mas como sendo condicional a certos intervalos, estes determinados historicamente (Moreira, 2006).

Como seriam expressos os pontos de bifurcação em modelos econômicos específicos? De forma geral, pode-se afirmar que qualquer modelo econômico apresenta um vetor de parâmetros estruturais que estabelece a natureza e o grau de correlação entre as variáveis dependentes e independentes do modelo. Os modelos concedem os valores de equilíbrio, ou o processo de ajustamento para o equilíbrio, mediante as suas variáveis independentes e o seu vetor de parâmetros estruturais.

Em uma realidade ergódica, os valores dos parâmetros estruturais, calculados mediante estimação estatística, a partir de séries históricas temporais ${ }^{30}$ devem ser iguais aos encontrados a partir de séries históricas espaciais. ${ }^{31}$ Pode-se dar o seguinte exemplo: em uma realidade ergódica, o coeficiente (parâmetro) de sensibilidade que relaciona as variações anuais do consumo às variações anuais da renda ${ }^{32}$ deve ser o mesmo:

Figura I

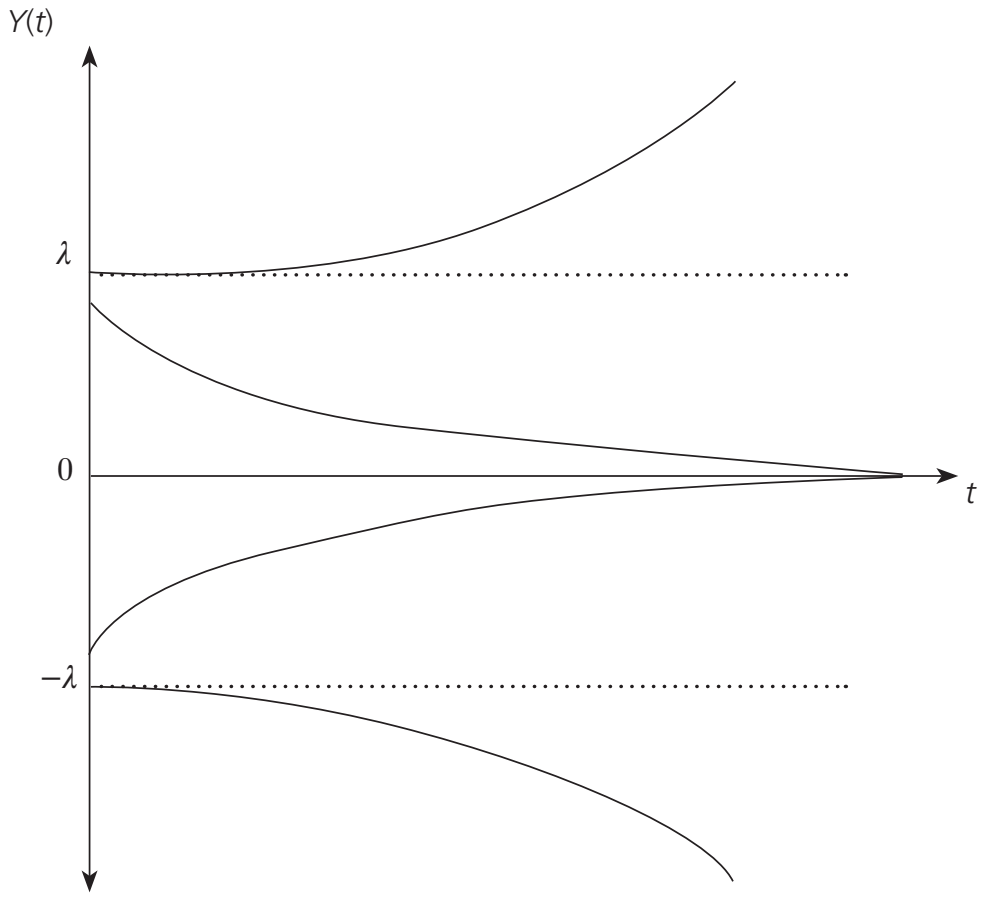


(a) para um teste que utilize as séries históricas temporais das duas variáveis (consumo e renda), originadas em um país específico, num intervalo de anos suficiente qualquer;

(b) para um teste que utilize as séries históricas espaciais das duas variáveis, originadas em um conjunto suficiente de países, num ano específico qualquer. Neste caso, observam-se as seguintes características:

(i) Sendo a realidade ergódica, não existem modificações estruturais no sistema econômico, as leis econômicas são universais e, portanto, os parâmetros estruturais encontrados são os mesmos para testes temporais e espaciais. ${ }^{33}$

(ii) Não existem bifurcações, uma vez que a estrutura qualitativa da economia é imutável no tempo. Nas palavras de Davidson (1996), tratase de uma realidade imutável, cuja estrutura não pode ser mudada pela ação humana.

Todavia, rejeitada a hipótese de ergodicidade, espera-se que haja diferenças entre os parâmetros estruturais encontrados nos testes estatísticos temporais e espaciais. Essas diferenças apareceriam porque, neste último caso,

- num mesmo país ou localidade há mudanças estruturais através do tempo;

- num mesmo período de tempo existem diferenças qualitativas entre os diversos países ou localidades. Diferenças em razão de especificidades institucionais, culturais, psicológicas etc.

O fato de não haver ergodicidade no sistema econômico tona-o passível de experimentar pontos de bifurcação, a partir dos quais seu vetor de parâmetros sofre modificações e, assim, as informações passadas e correntes - sobre as variáveis do modelo em questão — não são suficientes para a previsão, com confiança, do comportamento futuro da economia.

Em sua Teoria Geral, por exemplo, Keynes (1936) faz uso de certos parâmetros supostos como constantes - embora ele tivesse consciência de suas modificações com o tempo. Dentre esses dados podemos citar a técnica de produção, a quantidade e a qualidade de capital fixo, assim como o estado das expectativas de longo prazo (Kregel, 1976). Ao analisar a determinação da demanda efetiva sob o conceito de equilíbrio estático e estacionário, Keynes supõe, em especial, que não existe interdependência entre as frustrações nas expectativas de curto prazo e as expectativas de longo prazo. Em certo 
sentido, pode-se afirmar que nos modelos de equilíbrio estático e estacionário não ocorrem mudanças estruturais, pelo que o ponto de demanda efetiva permanece fixo no tempo: ou seja, a meu ver, neste caso, o sistema não experimenta pontos de bifurcação.

É no modelo de equilíbrio móvel que o sistema econômico visualizado por Keynes ganha seu caráter mais dinâmico (Kregel, op. cit.). As expectativas de curto e longo prazo são interdependentes. Frustrações nas expectativas de curto prazo modificam as expectativas de longo prazo. É possível dizer que, no modelo de equilíbrio móvel, o vetor de parâmetros estruturais do modelo de Keynes sofre modificações endógenas.Seja o seguinte vetor de parâmetros estruturais para o modelo da Teoria Geral:

$$
v_{t}=\left(T, K^{q}, K^{b}, E l_{t}\right)
$$

Sendo $v$ o vetor de parâmetros estruturais, $T$ a técnica de produção (constante), $K^{q}$ a quantidade de capital (constante), $K^{b}$ a qualidade de capital (constante) e $E l$ o estado de expectativas de longo prazo (variável). Seja a função:

$$
E l_{t}=E l_{t-1}+d E l / d t+\phi
$$

O estado de expectativas de longo prazo no período $t$ é uma função desse mesmo estado no período $t-1$, de variações endógenas ao longo do tempo $(d E l / d t)$ e de choques exógenos, representados por $\phi$. Ademais:

$$
d E l / d t=f(d E c / d t), \text { sendo } f^{\prime}>0
$$

Variações nas expectativas de curto prazo $(d E c / d t)$ criam variações, no mesmo sentido, ${ }^{34}$ nas expectativas de longo prazo $(d E l / d t)$. Ademais:

$$
d E c / d t=\pi(D-Z) \text {, sendo } \pi>0
$$

Assim, as variações nas expectativas de curto prazo dependem da relação entre a demanda agregada $D$ e a oferta agregada $Z$. Quando $D=Z$, tem-se que $d E c / d t=d E l / d t=0$, ou seja, está havendo uma realização das expecta- 
tivas de curto prazo, pelo que estas permanecem constantes (suas variações são nulas). Isso faz com que as expectativas de longo prazo não sofram modificações endógenas $(d E l / d t=0)$.

A partir das equações 1-4, chega-se a:

$$
E l_{t}=E l_{t-1}+f[\pi(D-Z)]+\phi
$$

As expectativas de longo prazo têm um componente de inércia $\left(E l_{t-1}\right)$, relativo ao seu estado no período $t-1$, um componente endógeno ( $f$ [ $\pi$ $(D-Z)]$ ), relativo à relação entre a demanda agregada e a oferta agregada, $\mathrm{e}$ um componente exógeno $(\phi)$, relativo a fatores psicológicos não associados ao comportamento corrente da economia. Finalmente, tem-se que:

$$
v_{t}=\left\{T, K^{q}, K^{b},\left(E l_{t-1}+f[\pi(D-Z)]+\phi\right)\right\}
$$

No modelo de equilíbrio móvel, o vetor de parâmetros estruturais sofre modificações endógenas, pelo fato de que mudanças nas expectativas de curto prazo - causadas pelos desequilíbrios entre $D$ e $Z$ - alteram o estado das expectativas de longo prazo. ${ }^{35}$ Trata-se da ocorrência do fenômeno de path-dependence e da existência de mudanças estruturais endógenas do sistema, as quais, por sua vez, podem ser descritas em termos de pontos de bifurcação. Pontos de bifurcação são manifestados quando, por fatores endógenos ou exógenos, $v_{t-1} \neq v_{t}$.

\subsection{Modificações estruturais e regimes de regulação: \\ o modelo de Harrod como um case pertinente}

A partir das várias versões do modelo de Harrod (37, 38, 39, 48, 73), tornase possível apresentar o sistema econômico como um processo histórico, cujas flutuações, determinadas endogenamente, ${ }^{36}$ possuem correlação com a estrutura qualitativa do sistema. Ou seja, torna-se possível a verificação teórica do fenômeno de path-dependence. De certa forma, isso equivale à análise de Kregel (1976) com base no que ele chama de "modelo de equilíbrio móvel", visto a seguir.

Mais precisamente, Kregel analisa os três tipos de equilíbrio derivados da Teoria Geral de Keynes: o estático, o estacionário e o móvel. O equilí- 
brio estático é aquele que ocorre quando as expectativas de curto prazo dos agentes são realizadas, não havendo correlação entre essas expectativas e as de longo prazo; o equilíbrio estacionário representa situações nas quais as expectativas de curto prazo não são satisfeitas, porém, a exemplo do que acontece no equilíbrio estático, as expectativas de curto e longo prazo são não correlacionadas. Neste caso, há um ajustamento de curto prazo por parte dos agentes em face do desequilíbrio, mas esse ajustamento não altera as expectativas de longo prazo, uma vez que não existe interdependência entre ambos os tipos de expectativas (curto e longo prazo).

O equilíbrio móvel, que mais se aproxima de uma visão historicista da economia, mostra situações de desequilíbrio em que expectativas de curto prazo não são satisfeitas, cujos processos de ajustamento aos quais dão origem têm influência sobre os valores a longo período. Neste sentido, há pathdependence, as decisões correntes dos agentes formam o estado futuro e não é possível fazer uma separação entre as flutuações e a estrutura qualitativa do sistema. Encore, rompe-se com a dicotomia ciclo/tendência (Herscovici, 2002). É com o conceito de equilíbrio móvel que o modelo de Harrod recebe uma dinâmica não linear.

Por motivo de simplificação, propõe-se o modelo de Harrod (1938) segundo o esquema apresentado por Herscovici (2002c):

(i) $G$. $C=s$, onde $G=\Delta Y / Y, C=\Delta K / \Delta Y$ e $s$ é a propensão marginal a poupar. $G$ é a taxa efetiva de crescimento do produto, enquanto $C$ é o coeficiente efetivo de capital, que Harrod considera constante ( $C=$ constante); $Y$ é o produto e $K$ o capital.

(ii) Logo, G.C $=\Delta K / Y$. Como $\Delta K=I$, sendo $I$ o investimento, tem-se que:

(iii) $G . C=I / Y=s Y / Y=s$, uma vez que a poupança, ex post, é considerada igual ao investimento.

(iv) Em seguida, apresenta-se $G w \cdot C r=s$. Sendo $G w$ a taxa garantida de crescimento do produto, ou seja, aquela taxa que, se fosse alcançada, deixaria os empresários sem estímulo para alterarem suas posições (Harrod, 1938). Por sua vez, Cr representa o coeficiente de capital desejado pelos agentes com base em suas expectativas de lucro. 
Os desequilíbrios de curto prazo são determinados por desvios entre a taxa efetiva de crescimento e a taxa garantida (entre G e Gw). Como G.C= $G w . C r=s$, caso $G>G w$, então $C<C r$ e os empresários terão estímulos para aumentar os investimentos. Todavia, via interação entre o multiplicador e o acelerador, haverá um aumento na taxa efetiva $G$, fazendo com que o desvio inicial entre $G$ e $G w$ seja ampliado, e assim também entre $C$ e $C r$. Esse processo de expansão cumulativa é caracterizado por um excesso de demanda, ou seja, por uma escassez de poupança diante do investimento corrente.

Caso, de maneira oposta, $G<G w$, tem-se que $C>C r$ e haverá redução dos investimentos. Cria-se um processo de recessão cumulativa, em que há excesso de oferta, ou uma escassez de investimento diante da poupança corrente. Não é surpresa que para Harrod, "superprodução é a conseqüência de a produção se situar abaixo do nível garantido” (Herscovici, 2002c: 16).

Para Herscovici (op. cit.), não existem razões para supor que $G=G w$, e que $C=C r$, uma vez que $G$ é realizado com base nas expectativas de lucro futuro dos empresários, ao passo que $G w$ seria a taxa que satisfaria aquelas expectativas. Em um universo de incertezas não mensuráveis, nada garante a realização de $G w$. A meu ver, quando $G$ é diferente de $G w$, a economia segue uma trajetória de crescimento fora do equilíbrio, na qual os agentes estão, a todo momento, revendo suas posições, uma vez que suas expectativas não são plenamente atendidas.

A questão com a qual se defronta é se $G w$ - a taxa que garante um crescimento equilibrado e que reflete, em algum grau, a estrutura qualitativa do sistema - permanece a mesma. A importância de uma hipótese sobre o comportamento de $G w$ pode ser vista mediante a tipologia oferecida por Kregel (1976), analisada acima. Embora uma suposta constância de $G w$ no modelo de Harrod, em contexto de equilíbrio estacionário, possa exibir processos de flutuações cumulativas (o princípio da instabilidade harrodiano), assim como a ocorrência de sensibilidade às condições iniciais, ${ }^{37}$ não é possível, com $G w$ invariável, visualizar a ocorrência dos ciclos, assim como a possibilidade de modificações estruturais do sistema e de mudanças no modo de regulação do mesmo. ${ }^{38}$

Por esse motivo, torna-se necessária uma análise que verifique a possibilidade de diferentes formas de regulação fora do equilíbrio. No modelo de Harrod isso acontece quando se permite a variação de $G w$ ao longo do 
tempo. É a existência de mecanismos alternativos de regulação, endógenos e exógenos, que pode tornar as flutuações não explosivas, determinandolhes um piso e um teto. Os investimentos públicos, de caráter contracíclico, são exemplos de reguladores exógenos, enquanto a propensão marginal a poupar (s) é um exemplo de regulador endógeno. Dessa maneira, define-se Gw assim:

$G w=(s-k) / C$, sendo $k$ o conjunto de estabilizadores contracíclicos exógenos.

Quando $G>G$ w, por exemplo, a propensão marginal a poupar $(s)$ aumenta e os gastos públicos se reduzem, fazendo $k$ diminuir. Logo, $G w$ aumenta e o seu desvio de $G$ é amenizado. Quando, ao contrário, $G<G w$, a propensão marginal a poupar (s) é reduzida e ké expandido; $G w$ diminui e também há um processo de regulação, muito embora não haja equilíbrio entre $G$ e $G w$.

Resta ainda uma importante reflexão sobre a hipótese, adotada por Harrod, de um coeficiente efetivo de capital constante, o que seria a base do princípio da instabilidade, impedindo o processo de convergência encontrado na versão neoclássica do modelo de Solow (1956). No modelo de Harrod, a constância do coeficiente efetivo de capital seria uma conseqüência da hipótese de uma taxa de juros constante (Jones, 1979), uma vez que:

$$
\begin{aligned}
& r=\Delta Y / \Delta K \\
& C=\Delta K / \Delta Y \\
& C=1 / r
\end{aligned}
$$

As três equações acima dizem o seguinte: no equilíbrio, segundo a ótica neoclássica, a taxa de juros $(r)$ é igual à produtividade marginal do capital $(\Delta Y / \Delta K)$. Por outro lado, o coeficiente de capital nada mais é do que a variação do capital, dada uma variação da renda $(\Delta K / \Delta Y)$. Assim, o coeficiente de capital é o inverso da taxa de juros. Se a taxa de juros é constante, o coeficiente efetivo de capital também se torna constante.

Nesse caso, sob a hipótese de uma taxa de juros constante, o processo de convergência para o crescimento equilibrado estaria impedido, já que, na presença de um desequilíbrio entre o coeficiente efetivo e o requerido, o valor do primeiro não poderia convergir para o valor requerido. A su- 
posta rigidez da taxa de juros em Harrod impede a ocorrência do princípio neoclássico da substitutibilidade dos fatores: como não existe uma perfeita flexibilidade da taxa de juros, que nada mais é do que o preço no mercado de capital, este último não consegue se equilibrar.

Todavia, mesmo se for aceita uma flexibilidade da taxa de juros, nada garante que as variações dessa última farão o coeficiente efetivo convergir para o valor (coeficiente) requerido, já que as variações do capital, ao dependerem do investimento, não são determinadas apenas pela taxa de juros, mas também, seguindo o pensamento de Keynes, pela eficiência marginal do capital. Esta última, por sua vez, depende das expectativas de longo prazo dos empresários. Assim, variações na taxa de juros podem ser acompanhadas por variações na eficiência marginal do capital, da tal forma que o coeficiente efetivo permaneça constante ou, se variável, não venha a variar na medida necessária para o processo de convergência para o equilíbrio entre $C$ e $C r$.

O modelo de Harrod apresenta uma concepção interessante e pertinente acerca do fenômeno do crescimento econômico. Surgem as seguintes considerações:

(a) Diante da existência de incerteza, as determinações monetárias da taxa de juros, à la Keynes, e as influências das expectativas de longo prazo sobre os investimentos fazem com que nada garanta um processo de convergência para o crescimento equilibrado;

(b) Há ocorrência de path-dependence, uma vez que variações em $s$ ou $k$ modificam $G w$, que pode ser considerado um parâmetro estrutural no modelo de Harrod. A estrutura corrente do sistema, que, em certa medida, determina as ocorrências de curto prazo, foi estabelecida pelas variações que $G w$, s e $k$ sofreram no passado;

(c) $\mathrm{O}$ modelo de Harrod apresenta uma concepção não determinista do crescimento do produto: não existe, a priori, uma trajetória necessária para o produto ao longo do tempo. Essa trajetória será escolhida pelas decisões presentes (descentralizadas) dos agentes, que se expressam pelas várias possíveis relações entre $G$ e $G w$, e pelas variações em $s, k$ e $G w$. 


\section{CONSIDERAÇÃO FINAL: MUDANÇAS ESTRUTURAIS VERSUS AJUSTES INCREMENTAIS}

A existência de path-dependence no sistema econômico torna o futuro dependente das decisões descentralizadas dos agentes. O grande papel com o qual se defrontam as instituições é o de coordenar essas decisões, no sentido de realizar um projeto socioeconômico transparente e viável. Ao Estado, por exemplo, cabe a função de, mediante seus vários instrumentos de política econômica, elevar o investimento global a níveis compatíveis com taxas de desemprego desprezíveis ou, se possível, com uma taxa nula de desemprego (pleno emprego). A partir de então, impedir que o investimento apresente uma variância (volatilidade) demasiada em torno daquele patamar alcançado. Isso teria como função amortecer os ciclos econômicos.

Todavia, tudo isso não pode ser feito apenas com ajustes incrementais diante de uma já existente estrutura qualitativa do sistema. Se um determinado modo de regulação tem se mostrado ineficaz em face dos resultados almejados, torna-se necessária uma busca de estruturas alternativas, estas tendo sua pertinência determinada historicamente.

\section{NOTAS}

1. Esta se baseia em mostrar que toda a renda criada no processo de produção, na forma de rendimentos pagos aos fatores, retorna ao sistema sob a forma de gastos com os bens produzidos pelo sistema produtivo. O fluxo "real" de bens e serviços tem sua contrapartida no fluxo "monetário" de renda (Kregel, 1980: 33). A moeda é um mero véu sobre as trocas reais.

2. Os agentes, na média, acertam suas previsões. Ou seja, não há erros sistemáticos.

3. Os mercados se equilibram, instantaneamente, via plena flexibilidade de preços.

4. Os processos estocásticos são homocedásticos.

5. Isso equivale à hipótese ergódica, cuja explanação será melhor feita adiante.

6. Ao longo do artigo, os termos modificações estruturais, mudanças qualitativas ou mudanças na estrutura qualitativa do sistema são considerados sinônimos.

7. Para melhor entendimento deste debate, ver Carvalho (2003).

8. Segundo Feijó (1993), uma economia monetária de produção é aquela em que: (a) como o futuro é incerto, os agentes assumem contratos monetários para tentar controlá-lo de alguma forma; (b) pelo fato de que as obrigações são expressas e pagas em moeda, a retenção desta tem um efeito psicológico positivo sobre os agentes; (c) a não-neutralidade 
da moeda implica a possibilidade de que a demanda efetiva seja inferior à oferta agregada potencial da economia, o que resulta na ocorrência de desemprego involuntário.

9. Conferir de igual modo Davidson (1999) e Kregel (1980).

10. Para efeito deste trabalho, flutuações econômicas são variações na renda e no emprego que acontecem fora do equilíbrio entre oferta e demanda agregadas, ou entre poupança e investimento globais.

11. Conferir Davidson (2003).

12. Para que a moeda tenha esta propriedade, é necessário que ela não seja uma mercadoria produzível pelo setor privado. Na época histórica sob vigência do padrão-ouro, portanto, a moeda mercadoria não possuía uma elasticidade de produção tão desprezível como a que se verificava nos anos 30. Todavia, Marx já definira a moeda como uma relação social, um equivalente geral, cujas funções podem ser desempenhadas por ativos não produzíveis pelo trabalho, muito embora ela sempre expresse o valor do trabalho. Ademais, para efeitos deste artigo, define-se moeda como um ativo não produzível pela indústria.

13. Supõe-se que o valor da moeda seja estável no tempo, motivo pelo qual os agentes aceitariam denominar contratos em moeda. Essa estabilidade em seu valor é a causa da liquidez da mesma, e sua âncora está em suas duas propriedades essenciais descritas acima.

14. Mesmo considerando o papel do poder judiciário em fazer valer os contratos econômicos, o comportamento cíclico da inadimplência contratual pode ser observado na maioria das economias desenvolvidas.

15. Esta análise segue Herscovici (2002: 268-269).

16. Adota-se a hipótese de que, em Keynes, pode haver uma desigualdade apenas ex ante entre poupança e investimento, muito embora ex post a poupança seja sempre igual ao investimento (Herscovici, 2002c). Essa convergência, contudo, se dá pelas variações da renda, e não por mudanças na taxa de juros. Pontos em que, ex ante, há diferença entre poupança e investimento representam situações fora do ponto de demanda efetiva (oferta agregada diferente da demanda agregada e, assim, poupança diferente do investimento). O sistema, entretanto, tende a convergir para este ponto, mediante as mudanças na renda e no emprego. Deve-se frisar que, diferentemente da abordagem neoclássica, em Keynes é a variação do investimento que gera alterações na poupança, a partir das mudanças prévias na renda. Conferir Moreira (2005).

17. Relativas à produção corrente, dado o capital existente.

18. Relativas à decisão de novos investimentos. Diz respeito à demanda esperada, dada uma mudança planejada no estoque de capital fixo.

19. Para uma melhor análise do modelo de Harrod (1938, 1939, 1948), conferir Herscovici (2002c).

20. Ferrari (2001: 170).

21. Termo usado por Prigogine (1996). 
22. Filho e Araújo (2000: 4).

23. A ergodicidade também implica: (a) a freqüência relativa de um evento $X$ é a mesma em qualquer ponto do tempo e (b) não há mudanças qualitativas do sistema. Conferir Herscovici (op. cit.).

24. Davidson (1996: 479).

25. No capítulo 14 de sua Teoria Geral, Keynes entra em maiores detalhes sobre a determinação e natureza da taxa de juros na teoria clássica. O erro básico desta teoria estaria em considerar a taxa de juros como a recompensa pela espera, ou pela renúncia ao consumo presente, em vez de considerá-la, como fez o próprio Keynes, como a recompensa pelo não-entesouramento da moeda. Keynes rompe de duas maneiras com a concepção clássica sobre a taxa de juros: (a) ao não atribuir à poupança e ao investimento a responsabilidade pela determinação dessa taxa, mas à oferta monetária e à preferência pela liquidez; (b) ao reconhecer de forma efetiva a correlação positiva entre investimento e nível de renda, o que não era aceito pela teoria clássica; nesta, uma variação do investimento é acompanhada de uma variação no consumo, via sinalização dos juros, de tal maneira que a renda permanece constante (Keynes, op. cit., cap. 14).

26. Embora pareça de difícil entendimento este argumento, o processo é idêntico ao usado para o estudo microeconômico das decisões da firma e do consumidor.

27. Em oposição ao comportamento criativo, este capaz de alterar a estrutura do sistema em que o agente está inserido.

28. Dequech (1999: 93) defende duas dimensões da incerteza: a dimensão ontológica referese à natureza complexa e irreversível da realidade econômica, ao passo que a dimensão epistemológica refere-se ao caráter limitado das capacidades cognitivas dos agentes. A ontologia tem como objeto de estudo a natureza da realidade.

29. O comportamento caótico seria representado por um sistema que possui uma hipersensibilidade às condições iniciais: pequenas alterações, por menores que sejam, na posição do sistema criam trajetórias radicalmente distintas a longo prazo. No sistema econômico, embora possa não ser considerada a regra, comportamentos caóticos podem emergir em determinados períodos históricos, tais como os períodos de guerra e hiperinflações.

30. Coleta-se uma única observação da variável $X$ em cada período de tempo (semana, mês, ano etc.).

31. Coletam-se suficientes observações da variável $X$ num momento fixo do tempo.

32. Em outras palavras, estamos falando da propensão marginal a consumir. O próprio Keynes observou que este parâmetro, de natureza psicológica, variava segundo o nível de renda da sociedade. Quanto maior o nível de renda de uma sociedade, menor seria a propensão marginal a consumir. Neste sentido, Keynes concebia o sistema econômico como suscetível de mudanças estruturais e de uma natureza não-ergódica.

33. Possíveis diferenças seriam de caráter aleatório, em razão de falhas de apuração ou coleta de dados ou de cálculo estatístico. 
34. Melhorias nas expectativas de curto prazo tornam as expectativas de longo prazo mais otimistas, e uma piora nas primeiras torna essas últimas mais pessimistas.

35. Obviamente, neste caso, também há uma mudança nos investimentos agregados, dados a taxa de juros e o preço de oferta dos bens de capital.

36. Isto não significa que as flutuações têm origem apenas endógena. É possível que parte das flutuações seja de origem exógena, cujos determinantes não são ainda conhecidos. Todavia, o importante é que o sistema de mercados não garante endogenamente uma trajetória equilibrada à economia.

37. Refere-se ao fato de que, no modelo Harrod com Gw constante, um desvio inicial de $\mathrm{G}$ em relação a $G w$, por menor que seja, gera trajetórias radicalmente distintas a longo prazo.

38. Neste caso, não haveria pontos de bifurcação.

\section{REFERÊNCIAS BIBLIOGRÁFICAS}

AMADEO, E. J., DUTT, A. K. (2003) “Os keynesianos neo-ricardianos e os pós-keynesianos”. In: Macroeconomia do emprego e da renda: Keynes e o keynesianismo. São Paulo: Manole.

BARBOSA, E. S. (1992) "Uma exposição introdutória da macroeconomia novo-clássica”. In: Silva, M. L. Moeda e Produção: teorias comparadas. Brasília: UNB.

CARVALHO, F. C. (2003) "Keynes e o longo período". In: Macroeconomia do emprego e da renda: Keynes e o keynesianismo. São Paulo: Manole.

(1992) "Moeda, produção e acumulação: uma perspectiva pós-keynesiana”. In: Moeda e produção: teorias comparadas. Brasília: UnB.

DAVIDSON, P. (2003) “Resgatando a revolução keynesiana”. In: Macroeconomia do emprego e da renda: Keynes e o keynesianismo. São Paulo: Manole.

(1999) “Colocando as evidências em ordem: macroeconomia de Keynes versus velho e novo keynesianismo”. In: Sicsú, J. Macroeconomia moderna: Keynes e a economia contemporânea. Rio de Janeiro: Campus.

(1996) "Reality and economic theory". Journal of Post Keynesian Economics, v. 18, n. 4. Summer.

DEQUECH, D. (1999) “Incerteza num sentido forte: significado e fontes”. In: Sicsú, J. Macroeconomia moderna: Keynes e a economia contemporânea. Rio de Janeiro: Campus.

DUMÉNIL G., LÉVY, D. (2001) “Desequilíbrio e estabilidade: proporções e dimensão”. Revista Perspectiva Econômica. Departamento de Economia da UFES, Vitória, ano II, v. I, n. 1, fev.

FERRARI, M. A. (2001) "Uma análise da macroeconomia novo-clássica”. Revista Perspectiva Econômica 1, Vitória, UFES, ago.

FERRARI, F. F., CONCEIÇÃO, O. A. (2001) "A noção de incerteza nos pós-keynesianos e institucionalistas: uma conciliação possível?”. Nova Economia, Belo Horizonte, 11 (1): 99-122, jul. 
FILHO, F., ARAÚJO, J. P. (2000) “Caos, incerteza e teoria pós-keynesiana”. Anais do V Encontro Nacional da Sociedade de Economia Política, set.

HARROD, R. F. (1937) “Mr Keynes and traditional theory”. In: Keynes' General Theory. Reports of Three Decades. Londres: Robert Lekachman, Macmillan \& Co LTD.

- (1938) "An essay in dynamic theory: 1938 draft". Daniele Besomi (ed.). History of Political Economy 28: 2.

(1939) "An essay in dynamic theory". The Economic Journal, March.

(1948) Towards a Dynamic Theory. Some recent Developments of Economic Theory and their Applicatyions to Policy. Londres: MacMillan.

- (1973) Economic Dynamics. Londres: MacMillan.

HERSCOVICI, A. (2004) "Irreversibilidade, incerteza e Teoria Econômica. Reflexões a respeito do indeterminismo metodológico e de suas aplicações na Ciência Econômica”. Estudos Econômicos, v. 34, n. 4.

- (2003) "Historicidade, entropia e não linearidade: algumas aplicações possíveis na Ciência Econômica”. Anais do XXXI Encontro Nacional da Anpec, Porto Seguro, dez.

- (2002) "Dinâmica macroeconômica: uma interpretação a partir de Marx e de Keynes”. Vitória: Ediufes.

- (2002b) “Economia do desequilíbrio, preços e instituições”. Revista Ensaios (FEE), Porto Alegre, v. 23, n. 1, p. 57-76.

- (2002c) "O modelo de instabilidade de Harrod: uma abordagem em termos de não linearidade”. Textos do Grupo de Estudos em Macroeconomia (GREM), Vitória (mimeo).

JONES, H. G. (1979) Modernas teorias do crescimento econômico: uma introdução. São Paulo.

KEYNES, J. M. (1973) The General Theory and After: preparation. Londres: Macmillan (The Collected Writings of John Maynard Keynes, v. XIII).

(1982) “A Teoria Geral do Emprego, do Juro e da Moeda”. São Paulo: Atlas. (1. ed. em inglês, 1936).

KREGEL, J. (1980) "Markets and institutions as features of a capitalistic production system". Journal of Post-keynesian Economics, v. III, n. 1. Fall.

- (1976) "Economic methodology in the face of uncertainty: the modelling methods of Keynes and the post-keynesians". The Economic Journal, Jun.

MOREIRA, R. R. (2006) “Relativizando o dilema estabilidade versus instabilidade: Keynes, o mainstream e o conceito de bifurcação em Economia”. Revista de Economia, v. 7, n. 1, jan./abr.

_ (2005) “A 'derrota da lei de Say': elementos teóricos fundamentais e algumas implicações metodológicas e dinâmicas”. Revista de Economia Contemporânea, v. 9, n. 2, p. 411-431, ago.

PRIGOGINE, I. (1996) “O fim das certezas: tempo, caos e leis da natureza”. São Paulo: Editora da Universidade Estadual Paulista.

SAY, J. B. (1803) “Tratado de economia política”. São Paulo: Nova Cultural (1. ed. em francês, 1803). 
SOLOW, R. M. (1956) “A contribution to the theory of economic growth". Quarterly Journal of Economics, v. 70.

VERCELLI, A. (1991) "Methodological foundations of macroeconomics: Keynes and Lucas". Londres: Cambridge University Press. 